\title{
Ese lugar debe ser tan bello como los colores que nacen en Chamula
}

\author{
Jaqolbe Lucrecia García Durán
}

Axel KöHler ET AL., 2010

Sjalel kibeltik. Sts'isjel ja kechtiki'. Tejiendo nuestras raíces

Universidad de Ciencias y Artes de Chiapas, Centro de Investigaciones y Estudios Superiores en Antropología Social, Programa Universitario México, Nación

Multicultural, México, 400 pp.

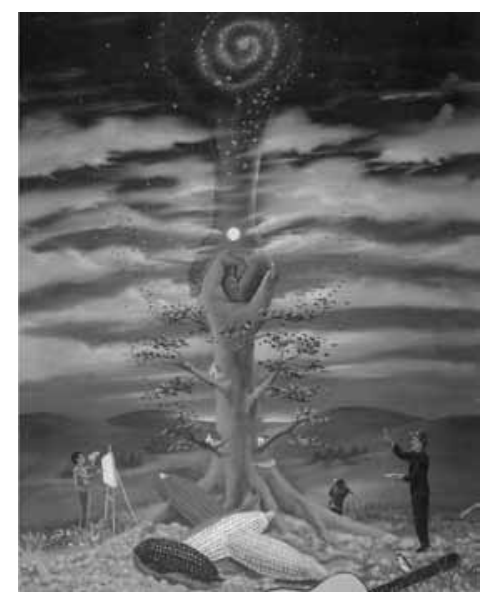

Al igual que en Topoxté, ${ }^{1}$ las raíces de nuestras raíces cubrieron y protegieron lo que ahora estamos viendo y viviendo. No cabe duda de que lo maya es generador de creatividad. Jaqolb’e Lucrecia García

${ }^{1}$ Topoxté, lugar de nuestras raíces, allá en Petén, cerca de Yaxja, la laguna color turquesa, donde los árboles se abrazaron y abrazaron las casas que ahora se denominan "ruinas".

That Place Must Be as Beautiful as the Colors Born in Chamula

JaQolb’e Lucrecia García Durán: Instituto de Estudios Humanísticos, Universidad Rafael Landívar, Guatemala, Guatemala jaqolbe@gmail.com

Desacatos, núm. 40, septiembre-diciembre 2012, pp. 187-189
$\mathrm{L}$ os diez coautores de este libro se preguntaron: ¿quiénes somos? Yo también me pregunté: ¿quién soy yo para reseñarlo? En la medida en que iba apreciando los colores, el alma-maíz me atrapó, me jaló a la tierra y empecé a germinar con mirada de jaguar y me ubiqué en las casitas que nacieron en los coditos del gran árbol humanizado de la portada del libro. Desde ahí tomé los hilos de los pensamientos-sentimientos vertidos en formas diversas. Es tan significativo que el 16 de enero de 2008 -que en calendario maya era lajuj Kawoq-q'anyoq, Kab'e B'atz' y jwe' Misat-kej-, allá en Jobel-San Cristóbal de Las Casas, el rayo, el 
tejido y la autoridad convergieran y de ahí surgiera lo que hoy vemos escrito, fotografiado, pintado y hablado. Todo lo que es Sjalel kibeltik. Sts'isjel ja kechtiki. Tejiendo nuestras raíces. Los lugares tienen su espíritu y su energía, que llama y que convoca, ya sea para someter o para liberar la tarea que tenemos los humanos de interpretar para transformar.

¿Qué nos deja ver y sentir este libro? Hay varios elementos clave: la sistematización de la experiencia, los colores y las imágenes; la convergencia y organización de prácticas alternativas, que generan, combinan y resignifican metodologías; el gran potencial de las lenguas de los autores y del evidente en las fotografías, en las pinturas, en las voces y en la música. Hay una deconstrucción del ser en hacer otra vez. El libro nos lleva a ver y sentir quién es el sujeto que hurga, explora, escribe y (re)construye. Nos enseña que el corazón y la co-razón son elementos clave para el renacimiento espiritual, que están abonados con tierra, maíz, sueños y con la palabra, a la par que liberados de ingredientes biológicos e ideológicos. Valora, a su vez, el derecho a la rebeldía.

El libro muestra la apropiación cultural de la tecnología para permanecer en la mente $o$ imaginario de los otros y las otras, ratifica la relación e interacción cultural que nos lleva a fortalecer nuestras relaciones interculturales críticas $y$ transformadoras, ${ }^{2}$ o como dicen los mismos coautores: "lo que nos hace iguales es que todos venimos de la Madre Tierra, somos de diferentes colores, pero eso no debería dividirnos, no debería lastimar el tronco del árbol”. El pintor Juan Chawuk, en el capítulo 2, se refiere a la universalidad y propone caminos como la abuelidad, reconocer los errores y aciertos de los papás y las mamás, así como desarrollar un estilo desde el corazón y la sexualidad. Damián Martínez, a través de un ejercicio cultural singular que contiene la revaloración del respeto y la inclusión. También muestra la regeneración de la conexión con la tierra y con el territorio,

\footnotetext{
2 Concepto que usamos en nuestro libro intitulado El encantamiento de la realidad. Conocimientos mayas en prácticas sociales de la vida cotidiana (Mendizábal, 2007).
}

director del grupo de bats'i rock Sak Tzevul, en el capítulo 3, dice al respecto: "a veces uno puede morir y volver a nacer por soñar tanto, de tal manera que los que soñamos demasiado tenemos varias vidas". Sin duda de que lo que estamos viendo y sintiendo son los abuelos y abuelas que están de vuelta en pleno siglo XxI.

El libro Sjalel kibeltik... nos invita a hacer la cuenta de las pruebas o de esos "megaviajes", como los llama Damián Martínez, por los que todos y todas pasamos para poder reconocer nuestras propias cenizas y cargarlas montaña abajo hasta que amanezca. Tampoco podemos perder la vista ni la visión, como diría en el capítulo 4 la violinista japonesa Rie Watanabe, hoy miembro de Sak Tzevul. Hay que aprender a nacer y salir de la boca de las montañas, olfateando la tierra, inspirando $\mathrm{y}$ transpirando juntos para descubrir el secreto del gozo desde la Raíz del Cuervo y el Pozo de Agua, diría el comunicador comunitario tsotsil José A. Jiménez, en el capítulo 5, zurciendo heridas, luchando por la equidad y la dignidad.

Este libro nos hace ver, sentir y hacer la siembra de otras formas de comunicar donde la voluntad se traduce en servicio, donde se es capaz de darle alma a algo, donde se lucha para que nuestros corazones no se endurezcan. El fotógrafo y sociólogo tzeltal Xuno López Intzín nos invita en el 


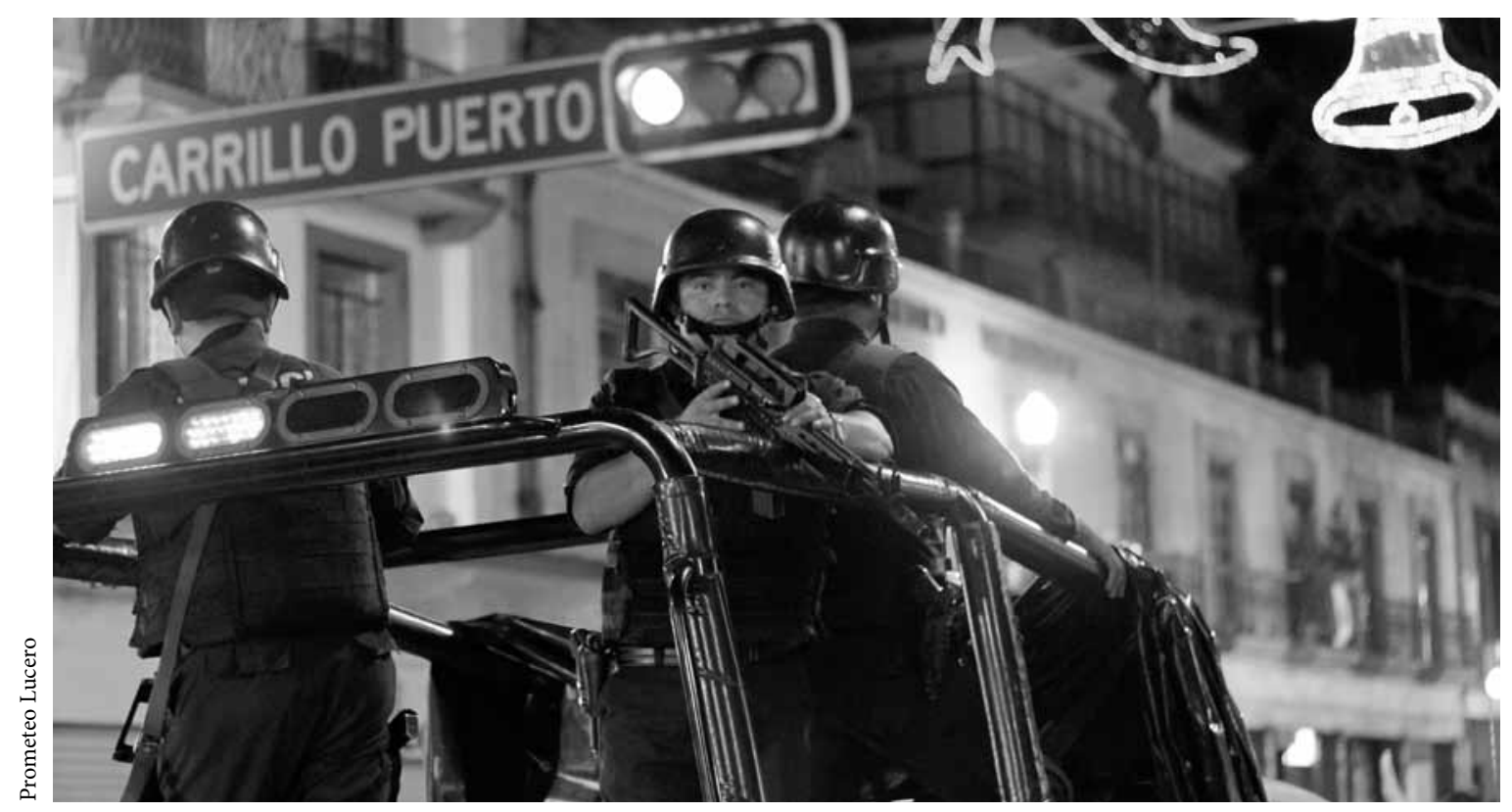

Policías estatales fuertemente armados custodian el paso de la Caravana al Sur del Movimiento por la Paz con Justicia y Dignidad, en Xalapa, Veracruz, después de un incidente, 18 de septiembre de 2011.

capítulo 6 al reencuentro en la tormenta. Nos invita a ir a donde se sigue convirtiendo a los impíos y a donde aún se vive la hostilidad de los conversos. Justo ahí la fotografía toma sentido para él, tal vez para recordarle qué estuvo bien y qué estuvo mal. Tal vez para que la memoria no muera.

Por su parte, el videoasta tsotsil Agripino Icó Bautista deja constancia en el capítulo 7 de una "mirada constante" por medio de la cual logra conectar diferentes dimensiones de la realidad cuando dice: "yo grabé el arbusto de una planta medicinal y las mujeres se fijaron en el detalle de las flores". Es en la práctica del ejercicio de la visión donde nace la conciencia y el complemento de las maneras de ver y de comunicar. Será por eso que todas y todos los autores de esta obra nos cuentan momentos difíciles en su proceso de hacerse humanos. Por ejemplo, el joven pintor tsotsil Ronyk nos hace llorar el alma en el capítulo 8 . Creo que todos, como él, deberíamos aprender a pintar, dibujar y colorear nuestra última casa: “el panteón”, porque de ahí nadie regresa: ese lugar debe ser tan bello como los colores que nacen en Chamula.

Vemos a Alex Köhler, en el capítulo 9, y a Xochitl Leyva Solano, en el capítulo 10, -grandes compañeros quienes han construido ese diálogo con los pueblos desde sus puebloscreando y generando perspectivas tierra adentro y tierra afuera, contribuyendo a la creación de identidades sólo para seguir siendo "hombres y mujeres verdaderos”. ¡Felicidades a las y los popl qnab'il - tejedores de sabiduría-! Kyaje Aj, kab'lajuj B’e.

\section{Referencias}

Mendizábal, Sergio (coord.), 2007, El encantamiento de la realidad. Conocimientos mayas en prácticas sociales de la vida cotidiana, Programa de Educación Intercultural Multilingüe de Centro América, Ministry for Foreign Affairs of Finland, Programa de las Naciones Unidas para el Desarrollo-Guatemala, Universidad Rafael Landívar (Colección Estudios Mesoamericanos), Guatemala. 